\title{
La inteligencia artificial al rescate de las pequeñas y medianas empresas
}

\section{Artificial intelligence to the rescue of small and medium enterprises}

\author{
RAMÍREZ-SOLANO, Nestor de Jesús $\dagger^{*}$, NIETO-ROSALES, Ana Laura, MARTÍNEZ-GONZÁLEZ, \\ Ana Stephany y VIDAL-HERNÁNDEZ, Cecilia
}

Instituto Tecnológico Superior de Acatlán de Osorio

ID $1^{\mathrm{er}}$ Autor: Nestor de Jesús, Ramírez-Solano / ORC ID: 0000-0001-5286-882X

ID $1^{\text {er }}$ Coautor: Ana Laura, Nieto-Rosales / ORC ID: 0000-0003-3059-9301

ID $2^{\mathrm{do}}$ Coautor: Ana Stephany, Martínez-González / ORC ID: 0000-0002-6979-3440

ID $3^{\text {er }}$ Coautor: Cecilia, Vidal-Hernández / ORC ID: /0000-0003-4475-0404

DOI: $10.35429 / \mathrm{JCT} .2019 .9 .3 .22 .34$

Recibido 25 de Abril, 2019, Aceptado, 02 de Junio, 2019

\begin{abstract}
Resumen
El presente trabajo, busca mostrar el uso de la inteligencia artificial como una opción dentro del comercio electrónico, esto con el fin de poder contribuir en el crecimiento y promoción de las ventas de las pequeñas y medianas empresas. La aplicación de la inteligencia artificial en el sector económico es muy amplio, por lo que en esta ocasión se interviene con una propuesta orientada a este sector. Por medio del presente desarrollo, se diseñó una aplicación móvil, donde se propone aplicar el uso de Machine Learning o aprendizaje automático a través de patrones, para implementar una aplicación capaz de reconocer imágenes y texto suministradas por los usuarios para vincularlos directamente con pequeñas y medianas empresas, que ofrecerán sus servicios y productos a través de la misma, permitiéndoles competir a la par con grandes empresas que tienen la solvencia económica para desarrollar sus propias aplicaciones de forma individual. El proceso para el desarrollo de la aplicación fue la metodología de Scrum, ya que derivado de la naturaleza del proyecto, se requería de la realización de cambios constantemente en el desarrollo del producto, por los Sprint.
\end{abstract}

Inteligencia artificial, Aplicación móviles, Aprendizaje profundo

\begin{abstract}
The present work seeks to show the use of artificial intelligence as an option within electronic commerce, this in order to contribute to the growth and promotion of sales of small and medium enterprises. The application of artificial intelligence in the economic sector is very broad, so this time is intervened with a proposal aimed at this sector. Through the present development, a mobile application was designed, where it is proposed to apply the use of Machine Learning or automatic learning through patterns, to implement an application capable of recognizing images and text provided by users to link them directly with small and medium companies, which will offer their services and products through it, allowing them to compete on a par with large companies that have the economic solvency to develop their own applications individually. The process for the development of the application was the Scrum methodology, since derived from the nature of the project, it was required to make constant changes in the development of the product, by the Sprint
\end{abstract}

Artificial intelligence, Mobile application, Deep learning

\footnotetext{
Citación: RAMÍREZ-SOLANO, Nestor de Jesús, NIETO-ROSALES, Ana Laura, MARTÍNEZ-GONZÁLEZ, Ana Stephany y VIDAL-HERNÁNDEZ, Cecilia. La inteligencia artificial al rescate de las pequeñas y medianas empresas. Revista de Tecnología Informática. 2019 3-9: 22-34
}

\footnotetext{
* Correspondencia del Autor (Correo electrónico: nestorsrj@ hotmail.com)

$\dagger$ Investigador contribuyendo como primer autor.
} 


\section{Introducción}

Actualmente el uso de la inteligencia artificial (IA) se está volviendo algo completamente normal ya que cada vez más objetos que nos rodean, hacen uso de esta o las aplicaciones que utilizamos día a día, todos ellos están ligados a una inteligencia artificial, destinados a analizar los gustos de los usuarios, sus intereses, la forma en la que piensan y hasta predecir lo que harán los usuarios.

Por lo que no es difícil imaginar que muchas empresas transnacionales utilicen los datos proporcionados por estos sistemas para lanzar ofertas o dirigir la publicidad a sus usuarios potenciales; un ejemplo claro es la bolsa de valores, en la cual la inteligencia artificial analiza todos los datos históricos y los actuales para predecir cómo se moverá la economía global, de esta forma se pretende disminuir al mínimo la posibilidad de que la bolsa caiga drásticamente como ha ocurrido en el pasado. Como podemos apreciar la inteligencia artificial tiene grandes implicaciones en el mundo actual en el que toda nuestra información está en línea y cada vez es más accesible a las instituciones interesadas en conocerla y que nosotros como personas cada vez dependemos más de la tecnología para realizar nuestras actividades diarias.

Por lo que en este trabajo, se estudia la utilización de Machine Learning o aprendizaje automático a través de patrones, para desarrollar una aplicación capaz de reconocer imágenes y texto suministradas por los usuarios, dichas imágenes estarán vinculadas con las características de los productos o servicios de un negocio. El enfoque está dado en utilizarse como un medio en el proceso de venta de las pequeñas y medianas empresas, donde ofrecerán sus servicios y productos a través de la aplicación.

\section{Implicaciones sociales y el comercio}

La IA está cambiando la forma en la que nos relacionamos con nuestro entorno impactando profundamente en nuestra sociedad. Por ejemplo, la IA puede estar presente en asistentes personales virtuales ya que conviviremos con chatbots interactivos que podrán sugerirnos productos, restaurantes, hoteles, servicios, espectáculos, según nuestro historial de búsqueda.

\section{1 ¿Cómo la IA ayudará a las pequeñas y medianas empresas (PyMES)?}

El uso de la inteligencia artificial en la economía es muy diverso, por lo que en este proyecto, nos orientaremos en el desarrollo de una propuesta como alternativa hacia este sector, en este mundo globalizado en el cual los pequeños y medianos negocios deben de competir a la par con las grandes transnacionales se recurre al uso de las tecnologías como el desarrollo de páginas web, el uso de redes sociales entre otras tecnologías para la promoción de sus negocios.

Además de la automatización de diversos procesos lo que disminuye en cierto modo los costos y tiempos de la realización de algunas actividades, además de ayudar a los consumidores a realizar sus compras de una manera más rápida y desde la comodidad de sus hogares.

Sin embargo, por algunos años ésta tecnología estuvo restringida y solo las grandes compañías nacionales o transnacionales podían costear su uso en las diversas actividades que desempeñaban tanto desde el proceso de la manufactura hasta el proceso de la comercialización de sus productos o servicios.

Pero en los últimos años la reducción de los costes de las tecnologías, al igual que su reducción de tamaño y ampliación de su potencial de procesamiento la IA se volvió más accesible para todos; y es tomando una IA disponible al público creada por Google llamada Google Visión, que se ha utilizado para diseñar una aplicación que hace uso de los procesos cognitivos de la IA para el reconocimiento de patrones, con la que se le ayudará a las pequeñas y medianas empresas a vender sus productos y servicios, haciendo que estas puedan competir con las empresas más grandes, sin la necesidad de recurrir a la inversión de una gran cantidad de dinero, para financiar proyectos de esta índole que les permite ser altamente competitivos.

La aplicación que hemos diseñado para apoyar a las PyMES, en la primera versión de la aplicación, se utiliza una IA con aprendizaje profundo en la nube para el reconocimiento de objetos y texto, es decir, el usuario toma una fotografía de cualquier objeto, después, la aplicación a través del reconocimiento de patrones clasifica la imagen en una categoría. 
Dichas categorías ya están definidas de acuerdo a la función o razón de ser del negocio, la imagen analizada, se vincula instantáneamente a un producto o servicio que promueve el negocio, dicho proceso de reconocimiento arroja con lo que al usuario se le muestra una lista de productos relacionados a la imagen que ingresó a la aplicación, haciendo que su proceso de búsqueda sea más eficiente lo que disminuye su tiempo de búsqueda además de que su satisfacción aumenta, permitiendo que usuario aproveche el tiempo ahorrado en la búsqueda para realizar otras actividades desde la comodidad de sus hogares o desde cualquier otra parte del mundo donde se encuentre con una conexión a internet.

Como se puede notar la aplicación diseñada para las PyMES trabajará de una forma más eficiente reduciendo la cantidad de tiempo para la búsqueda de productos y proporcionando las mejores opciones para los usuarios, con lo que le permitirá a las PyMES competir con empresas más grandes en este mundo globalizado en el cual no solo se compite con empresas en el mismo área geografía sino con empresas que se encuentran distribuidas alrededor del mundo.

En la segunda fase de la aplicación, con el uso de la IA aumentará ya que no solo se encargará de reconocer las imágenes y texto que el usuario le suministre, sino que además la aplicación tendrá la capacidad de aprender del usuario y mostrarle los productos que se encuentran en oferta o lo nuevo que se está vendiendo de acuerdo a las preferencias de los usuarios haciendo que cada uno tenga una experiencia personalizada.

\section{Marco teórico}

Firebase es la nueva y mejorada plataforma de desarrollo móvil en la nube de Google. Se trata de una plataforma disponible para diferentes plataformas (Android, iOS, web), dicho entorno de desarrollo, se utilizó para la programación de la aplicación, con la base en tiempo real de Firebase se guardaron todos los datos que requiere la aplicación. React y su patrón reactivo, permite actualizar los datos en los componentes automáticamente. Los datos se almacenan en formato JSON y se pueden agregar reglas para permitir requests con token o desde una URL.
Para la simplificación del inicio de sesión y acceso a la aplicación, se usó el proveedor de Google, esto con el fin de implementar la parte de autenticación de la App, garantizando un recurso más en el desarrollo de la seguridad a la misma.

La herramienta del Almacenamiento, se usó para subir imágenes desde un formulario ya que la base de datos, está configurada para que se pueda realizar dicha función.

El servicio de Hosting, con una colección de estáticos se pudo subir la aplicación y ésta automáticamente contará con SSL y HTTP2, ya que se tiene app con Angular o Firebase y por lo tanto se procedió hacer un build desde nuestros ordenadores y subir estos archivos generados.

Cloud Functions es un producto bastante reciente de Firebase que tiene como objetivo la transformación de nuestro código del backend en pequeñas piezas del mismo (funciones).

Estas funciones son creadas en NodeJS y se suben a la vez que hacemos deploy. Al crearse generan una URL a la que podemos llamar desde AJAX para que se ejecute el código pertinente. Firebase nos provee de unos triggers para comunicarnos con ciertas funciones de sus productos, así como un trigger de HTTP.

Para el proceso de prueba de la aplicación, se utilizó laboratorio de test para Android. Este servició nos ofreció la posibilidad de probar los test de nuestra aplicación en los entornos que configuremos (Especificar qué es lo que se configuró específicamente para el proyecto....).

Con Informes sobre fallos, se detectaron los errores que aparecieron en nuestra aplicación. Esta herramienta dio paso a Crashlytics de Fabric, que se integró como una herramienta más dentro de éste proceso.

La herramienta de Monitoreo de rendimiento, ayudó a medir el rendimiento de la aplicación y el tiempo que los usuarios pasan durante los diferentes procesos de la misma con el fin de que se pudiera detectar problemas en el tiempo de carga y prevenirlos. 


\subsection{El uso de API de cloud Vision}

La API de Cloud Visión nos permite comprender el contenido de una imagen al encapsular poderosos modelos de aprendizaje automático en una API. Clasifica rápidamente las imágenes en miles de categorías, detecta objetos y caras individuales dentro de las imágenes y lee palabras impresas contenidas en las imágenes. Puede crear metadatos en su catálogo de imágenes, moderar el contenido ofensivo o habilitar nuevos escenarios de mercadeo a través del análisis del sentimiento de imagen.

Proporciona una interfaz RESTful que facilita la tarea de tener que desarrollar algoritmos de procesamiento de imágenes. Visión API soporta formatos de archivo de imagen como JPEG, BMP, RAW, PNG. Para un análisis lo más preciso posible, la resolución de imagen mínima recomendada es VGA $(640 \times$ 480 píxeles), y el tamaño de los ficheros no debe superar los $4 \mathrm{MB}$.

\subsubsection{Proceso de detección de perspectiva de imágenes}

Se utilizó para detectar fácilmente conjuntos amplios de objetos de imágenes, dichas imágenes se pueden categorizar en flores, animales o transporte, entre otras categorías de objetos que se encuentran comúnmente en nuestro entorno.

Visión API mejora con el tiempo a medida que se introducen nuevos conceptos y se mejora la precisión. Con AutoML Visión, creando modelos personalizados que resalten conceptos específicos de las imágenes.

\subsubsection{Proceso de extracción de texto.}

El reconocimiento óptico de caracteres (OCR) le permite detectar texto dentro de las imágenes, junto con la identificación automática de idioma. Visión API soporta un amplio conjunto de idiomas, para éste proyecto se utilizó el idioma español.

\subsubsection{Búsqueda y actualización en la web}

Visión API utiliza el poder de la búsqueda de imágenes de Google para encontrar nuevas imágenes en la web, por lo que puede estar seguro de que las últimas imágenes relevantes están disponibles.
Se combina para este proyecto, la Búsqueda Visual Similar, para encontrar imágenes similares en la web.

\subsubsection{Reconocimiento óptico de caracteres (OCR)}

Con la utilización de la API de Visión, se pudo detectar y extraer texto de imágenes. De las dos características de anotación que admiten OCR fue: TEXT_DETECTION detecta y extrae texto de cualquier imagen. Por ejemplo, una fotografía puede contener una señal de tráfico o una señal de tránsito. El JSON incluye toda la cadena extraída, así como las palabras individuales y sus cuadros delimitadores.

\subsubsection{Especificando el idioma}

Ambos tipos de solicitudes de OCR admiten uno o más languageHints que especifican el idioma de cualquier texto en la imagen. Sin embargo, para fines prácticos de ésta investigación, se tomó un valor vacío ya que produjo un mejor resultado, ya que permite la detección automática del idioma.

\subsection{Metodología}

Para el desarrollo de la App, se utilizó una metodología del marco de desarrollos agiles SCRUM, para el desarrollo y proceso del sustento de la investigación, el trabajo tiene adoptado la una metodología mixta, aplicando los instrumentos de recolección de información la entrevista y encuesta, la primera busca identificar los requisitos funcionales $\mathrm{y}$ no funcionales para el desarrollo de la aplicación, la segunda es con el objeto de poder validar y verificar los aspectos de calidad del software, en el proceso de pruebas.

\section{Resultados}

\subsection{Representación del modelo de teoría}

Andreas Kaplan y Michael Haenlein definen la inteligencia artificial como "la capacidad de un sistema para interpretar correctamente datos externos, para aprender de dichos datos y emplear esos conocimientos para lograr tareas y metas concretas a través de la adaptación flexible" [Andreas Kaplan; Michael Haenlein, 2019]. 
A medida que las máquinas se vuelven cada vez más capaces, tecnología que alguna vez se pensó que requería de inteligencia se elimina de la definición. Por ejemplo, el reconocimiento óptico de caracteres ya no se percibe como un ejemplo de la «inteligencia artificial» habiéndose convertido en una tecnología común [Schank, Roger C., 1991]. Avances tecnológicos todavía clasificados como inteligencia artificial son los sistemas de conducción autónomos o los capaces de jugar al ajedrez o al Go [Andreas Kaplan; Michael Haenlein, 2018].

El aprendizaje profundo es una técnica de aprendizaje automático que utiliza redes neuronales (el concepto de que las neuronas se pueden simular mediante unidades computacionales) para realizar tareas de clasificación.

Algunos ejemplos de aplicaciones prácticas del aprendizaje profundo son las siguientes: identificación de vehículos, peatones y placas de matrícula de vehículos autónomos, reconocimiento de imagen, traducción y procesamiento de lenguaje natural.

En lo comercial la inteligencia artificial posibilita hacer pronósticos de ventas y elegir el producto adecuado para recomendárselo al cliente. Empresas como Amazon utilizan robots para identificar si un libro tendrá o no éxito, incluso antes de su lanzamiento.

Por lo que se propone una aplicación que integrara diversos recursos como lo son la inteligencia artificial de Google Visión, para realizar el clasificado y lectura de fotografías con el fin de que una vez clasificado el contenido de la imagen esta busque en la base de datos productos que le pueden interesar al usuario para su compra.

En este contexto, el modelo de teoría es estimular a la aplicación con datos externos en este caso con fotografías tomadas por los usuarios para que el sistema las clasifique y nos regrese como resultado productos relacionados con el tema con el que clasifico la fotografía que fue el estímulo inicial, con el fin de que el usuario pueda encontrar los productos que desea de una forma más eficaz, permitiendo reducir los tiempos en este sector de las ventas en línea para la pequeñas y medianas empresas.

\subsection{Descripción general del sistema}

Diseño e implementación de una solución inteligente de Aprendizaje Profundo en la nube para reconocimiento de objetos y compras, conectando servicios de empresas pequeñas y medianas en una aplicación móvil. El cual facilitará el proceso de búsqueda de productos en línea, con lo que el usuario tendrá la oportunidad de realizar otras actividades, desde la comodidad de sus hogares o desde cualquier otra parte del mundo donde se encuentre con una conexión a internet. Lo anterior se puede ver más claramente a través de una serie de pasos los cuales va desde la estimulación externa del sistema hasta que el usuario compra un artículo:

- $\quad$ Se inicia sesión a través de alguna de las tres formas admitidas por el sistema ya sea con una cuenta de google.

- Se toma la fotografía del objeto o texto el cual el sistema clasificara.

- Se muestra al usuario un catálogo de productos relacionados a la fotografía que tomo.

- $\quad$ El usuario puede escoger el producto que se más de su agrado y ver fotografías más grandes y la descripción del mismo.

- $\quad$ Al querer comprar un producto el usuario tendrá que introducir su dirección y datos bancarios para hacer exitosa la compra.

- Una vez realizada la compara o cancelada regresara a la ventana inicial donde podrá tomar otras fotografías.

\subsection{Diseño físico}

Como se describió en el marco teórico la metodología que utilice para desarrollar esta tesis es la metodología SCRUM la cual me permitió hacer varios ciclos de interacción para realizar los entregables que se presentaban a la empresa de MEXBALIA S. A., para la que se desarrolló la aplicación, además de que el proyecto fue tomado del banco de proyectos de la misma empresa.

Lo primero que se realizó al escoger el proyecto fue hacer la recolección de la información requerida para saber la situación actual en la que se encuentra el área a la que se orienta el proyecto realizado al igual de recolectar información para adquirir el conocimiento necesario, además de conocer a fondo las diversas tecnologías con las que se elaboró el proyecto.

RAMÍREZ-SOLANO, Nestor de Jesús, NIETO-ROSALES, Ana Laura, MARTÍNEZ-GONZÁLEZ, Ana Stephany y VIDALHERNÁNDEZ, Cecilia. La inteligencia artificial al rescate de las pequeñas y medianas empresas. Revista de Tecnología Informática. 2019 
Por lo que durante la primera etapa se realizaron exhaustivas investigaciones y se desarrollaron planes de cómo realizar el proyecto, por lo que se desarrolló el siguiente cronograma de actividades:

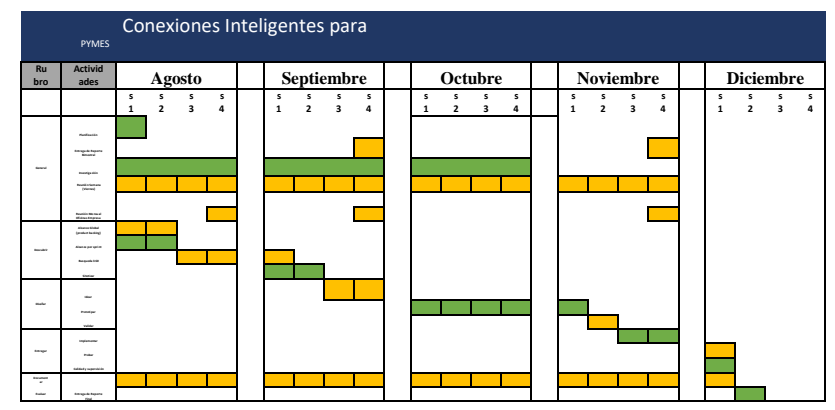

Figura 1 Cronograma de actividades

Como se puede apreciar en el cronograma de actividades en la primera etapa se realizaron los alcances globales o el product backlog el cual es el documento donde se plasma todos los requisitos a cumplir durante la elaboración del proyecto, priorizando su nivel de importancia, el costo del desarrollo, se define completamente el trabajo a realizar y representa en forma teórica como va a ser construido en su totalidad el proyecto por lo que en él se representan las diversas tareas y tiempos de ejecución de las mismas.

Una vez que se realizó el product backlog se realizan los alcances por sprint el cual consiste en dividir los requisitos en sub-tareas alcanzables en menos de 16 horas las cuales se realizan por los integrantes del proyecto de acuerdo a como ellos los vallan tomando, y los cuales al durar menos de 16 horas se tienen que entregar un conjunto de estos al final de la semana para que de acuerdo con el cronograma se muestren los avances realizados en las reuniones virtuales semanales y las reuniones mensuales presenciales que se tenían.

Otros aspectos que cubrían la primera etapa de la metodología era la búsqueda 360 la cual se refiere a que de todo lo buscado inicialmente se escogen solo los subtemas más importantes que tengan una mayor relación con el proyecto para profundizar aún más y posteriormente se llega al final de la primera etapa sintetizando y comprendiendo la información recabada.
Una vez terminado lo anterior se procede a la segunda etapa llamada diseño la cual cuenta con tres procesos los cuales son idear, desarrollo de prototipo y validar, el cual en nuestro caso solo fue necesario repetir este ciclo en dos ocasiones.

\subsection{Primer ciclo}

Basados en los requerimientos generales se tenía una idea inicial de cómo se iba a diseñar la aplicación por lo que se realizaron diseños preliminares para efecto demostrativo de los cuales los interesados del proyecto dieron sugerencias y realizaron cambios para acercar más el proyecto a la visión que ya tenían sobre el diseño.

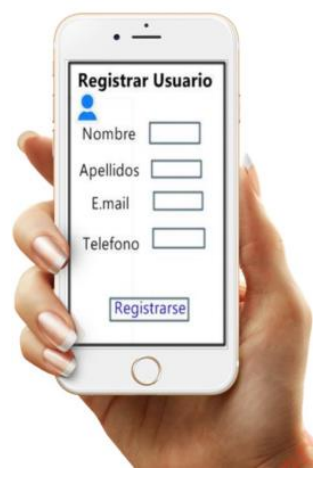

Figura 2 Registro de usuario

Como se puede apreciar en la Figura es un diseño creado en el programa SketchBook junto con el programa Screenshop Lite el cual muestra la interfaz de registro de usuario la cual se pretendía que una vez el usuario se registrara esta abriera automáticamente la sesión del usuario para poder usar la aplicación con los datos del registro.

Una vez que el usuario realizara lo anterior se abriría la siguiente interfaz de la aplicación.

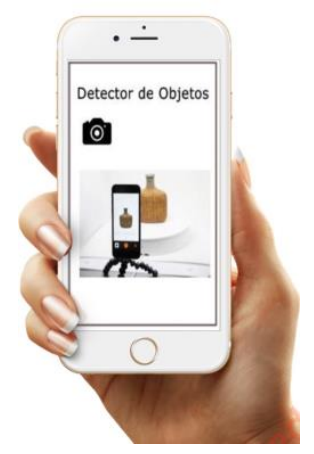

Figura 3 Detección de objetos

RAMÍREZ-SOLANO, Nestor de Jesús, NIETO-ROSALES, Ana Laura, MARTÍNEZ-GONZÁLEZ, Ana Stephany y VIDALHERNÁNDEZ, Cecilia. La inteligencia artificial al rescate de las pequeñas y medianas empresas. Revista de Tecnología Informática. 2019 
En la Figura 3 se muestra la interfaz que realizara el reconocimiento de objeto a través de fotografías que tome el usuario sobre los objetos que esté interesado en adquirir. Una vez realizado esto la aplicación realizara el reconocimiento del objeto y mostrara una ventana con una lista de todos los productos relacionados al objeto que detecto en la fotografía.

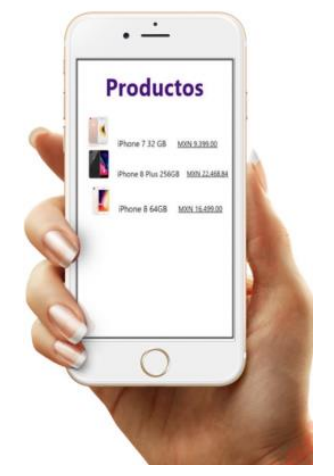

Figura 4 Lista de productos

En la Figura 4 se muestra la interfaz que mostrara la lista de productos disponibles relacionados con el objeto que detecto la aplicación en la fotografía, en este ejemplo se designó que el objeto detectado se un teléfono móvil por lo que en la lista solo aparecen celulares, que al hacer clic sobre la imagen o su nombre nos habrá otra interfaz que muestre más fotografías del producto seleccionado, una descripción más detallada del mismo y la opción de comprarlo como se muestra en la siguiente figura.

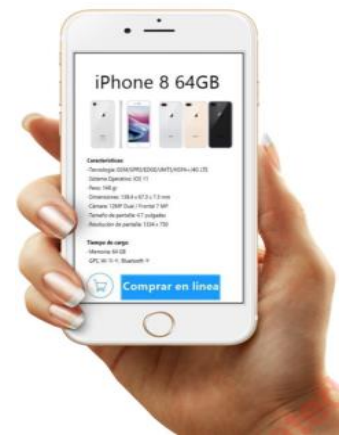

Figura 5 Características del producto

Ahora como apreciamos en la Figura 5 se puede ver una imagen más clara del producto que el usuario selecciono además de que muestra muchas de las características que los usuarios por lo regular les interesa saber de los productos que van a adquirir y finalmente en la parte de abajo aparece un botón para realizar la compra la cual en automático nos llevaría a las siguientes ventanas.

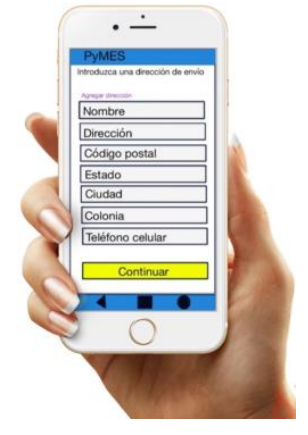

Figura 6 Dirección de envió

Una vez que hacemos clic en el botón de comprar producto la aplicación nos mostrara la interfaz que se aprecia en la Figura 6 en la cual es un formulario para ingresar los datos a donde de dirección donde el usuario quiera que se entregue su producto. Y una vez terminado este formulario solo faltaría la siguiente interfaz.

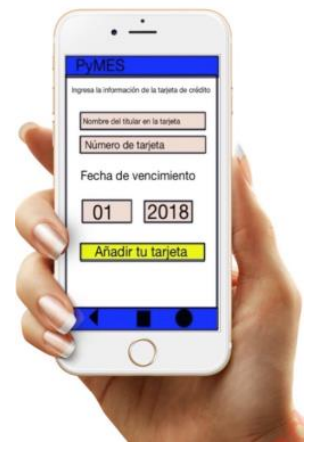

Figura 7 Información de pago

La última interfaz es la que se presenta en la Figura 7 en la cual el usuario escanea su tarjeta de crédito o débito y rellena la información faltante para realizar la compra exitosamente y una vez concluida esta regresara automáticamente a la interfaz de la Figura 3 para que el usuario pueda seguir buscando más productos. Lo anterior es todo lo relacionado a las interfaces de la aplicación que estarán en interacción directamente con el usuario, la otra parte es donde se almacena todos los datos de la aplicación que es la base de datos la cual para este primer ciclo quedo de la siguiente manera:

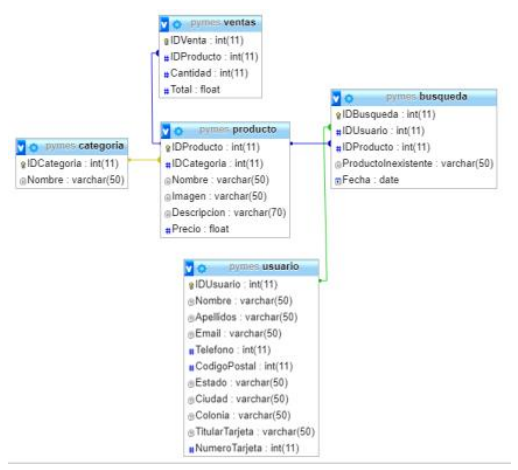

Figura 8 Base de Datos 1

RAMÍREZ-SOLANO, Nestor de Jesús, NIETO-ROSALES, Ana Laura, MARTÍNEZ-GONZÁLEZ, Ana Stephany y VIDALHERNÁNDEZ, Cecilia. La inteligencia artificial al rescate de las pequeñas y medianas empresas. Revista de Tecnología Informática. 2019 
Con lo anterior se concluye el primer ciclo de la segunda etapa de la metodología la cual los diseños fueron presentados a los representantes de la empresa de MEXBALIA S. A. en la segunda reunión mensual que se tuvo con ellos, en la que a partir de esa reunión se obtuvieron cambios y mejoras a realizar en las interfaces con lo que se inició el segundo ciclo de esta etapa y que se presentara a continuación.

\subsection{Segundo ciclo}

Como ya se mencionó anteriormente para este segundo ciclo se realizaron cambios en las interfaces de acuerdo con las observaciones tenidas en la segunda reunión mensual tenida con los representantes de la empresa MEXBALIA S. A., estos cambios fueron aplicados directamente sobre las interfaces finales en Android Studio como se mostrará a continuación:

Lo primero que se realizo fue la creación de un logotipo de la aplicación que al mismo momento funcionara como icono el cual se mostrara cuando la aplicación se instale en los dispositivos de los usuarios y en la página principal de la aplicación. Y este logotipo se realizó de tal manera que represente lo que la aplicación realiza por lo que el diseño final de este logotipo es el que se presenta en la Figura 9 el cual es una lupa que contiene un cerebro el cual tiene a su vez diversos dispositivos en su interior y por debajo de ese conjunto está el nombre de la aplicación creada al cual nombramos "IASHOP".

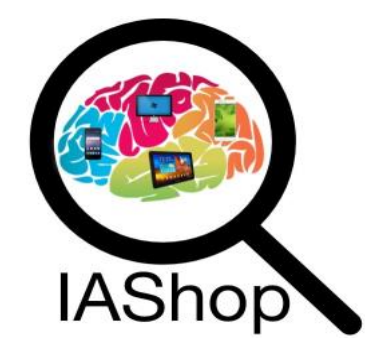

Figura 9 Logotipo de la aplicación

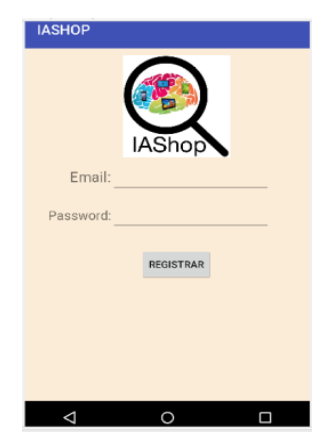

Figura 10 Inicio de Sesión

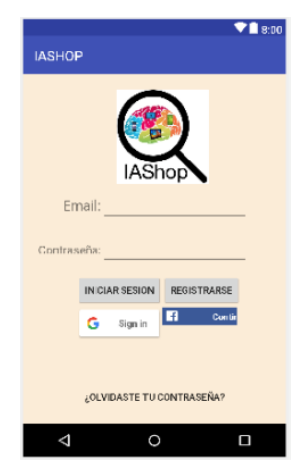

Figura 11 Registro modificado

Como se puede apreciar en la Figura 10 se ha desarrollado un inicio de sesión muy completo el cual tiene el logotipo de la aplicación en la parte superior central, en seguida se tiene los inicios de sesión el cual se puede realizar de tres formas distintas.

En primer lugar podemos acceder con un correo de cualquier compañía y una contraseña el cual debemos registrar previamente en el formulario de registro al cual podemos acceder al hacer clic en el botón registrarse y que se muestra en la Figura 11, o bien podemos hacer inicio de sesión con nuestra cuenta google que introdujimos en nuestro dispositivo cuando lo configuramos o bien hacer un inicio de sesión con nuestra cuenta de Facebook.

Y por último en el caso de que olvidemos la contraseña que registramos en el caso de los usuarios que inician sesión de esta manera pueden recuperar su contraseña haciendo clic en la pregunta de "¿olvidaste tu contraseña?" el cual lo re direccionará a una página web donde tiene que escribir su correo y para enviarle la contraseña al mismo.

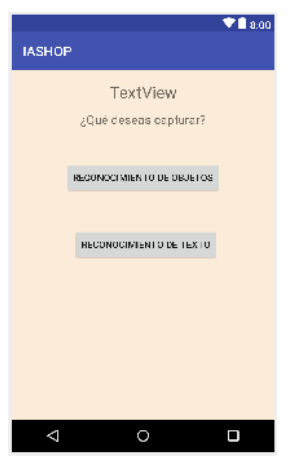

Figura 12 Interfaz Home
RAMÍREZ-SOLANO, Nestor de Jesús, NIETO-ROSALES, Ana Laura, MARTÍNEZ-GONZÁLEZ, Ana Stephany y VIDALHERNÁNDEZ, Cecilia. La inteligencia artificial al rescate de las pequeñas y medianas empresas. Revista de Tecnología Informática. 2019 


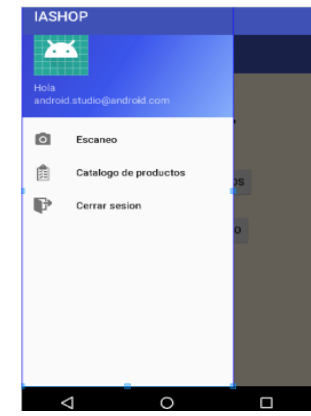

Figura 13 Barra lateral

Una vez que se inició sesión exitosamente con cualquiera de las tres formas mencionadas anteriormente el sistema abrirá la interfaz de la Figura 12 en la cual cómo podemos apreciar tiene dos cuadros de texto y dos botones, el primer cuadro de texto está reservado para poner el nombre del usuario o en su defecto el nombre del correo antes del arroba, esto se puede hacer porque desde que el usuario escoge una forma de inicio de sesión la aplicación automáticamente se conecta al servicio especificado ya sea google o Facebook haciendo la petición de obtener el nombre del usuario, su correo y una fotografía (en caso de tenerla si no la aplicación le asigna una predeterminada) todo esto para hacerlo más personalizado para cada usuario y en caso de ser un correo registrado en el formulario de registro como ya se mencionó solo se obtiene el nombre del correo.

El segundo cuadro de texto solo muestra una pregunta que es la de "¿Qué desea capturar?" esto es con el fin de guiar a el usuario para que seleccione alguno de los botones que lo llevaran a las interfaces que mencionan los botones ya sea el reconocimiento de objetos o el reconocimiento de texto. Otro elemento que se agregó en la interfaz de la Figura 12 es una barra lateral como se muestra en la Figura 13 en la cual cómo podemos apreciar contiene un elemento para imágenes que como se mencionó anteriormente esta contendrá la que el usuario tenga como fotografía de perfil en su cuenta de google o Facebook y en el caso de no tener ninguna la aplicación le designara una por defecto como a los usuarios que ingresen con un correo registrado en la misma aplicación.

Continuando con la barra lateral en el cuadro donde en la Figura 13 se muestra la palabra "Hola" se mostraría el nombre del usuario obtenido de la forma como ya se mencionó anteriormente posteriormente se mostrará el correo del usuario en la parte inferior.
En la segunda parte de la barra lateral se tienen tres botones más los cuales el primero llamado escaneo nos mostrara la interfaz de la Figura 12, el siguiente botón llamado catálogo de productos el cual nos mostrara como su nombre nos dice un catálogo completo de todos los productos existentes en la base de datos sin una clasificación específica y por ultimo tenemos el botón de cerrar sesión que como su nombre lo dice cerrara la sesión actual del usuario si así lo desea en caso contrario si no cierra sesión la aplicación mantendrá la sesión iniciada.

Como podemos apreciar de las cuatro interfaces ya mostradas de este segundo ciclo los colores predominantes en la aplicación son los colores entre los tonos azul y naranja, esto es debido que de acuerdo con la psicología de los colores el color azul representa confianza, que es lo que se quiere transmitir a los usuarios para que se sientan seguros de usar la aplicación y de proporcionar información delicada como lo es su dirección y cuenta bancaria, además de transmitir confianza a los usuarios con los tonos del color azul el usuario puede cerciorarse de que no se hará mal uso de sus datos personales a través de las políticas de privacidad diseñadas específicamente para esta aplicación.

Otro color que predomina en la aplicación es el naranja este color se usa con la finalidad de que el usuario compre dentro de la aplicación porque de acuerdo de nuevo con la psicología de los colores los tonos naranjas inducen a las personas a comprar, que es lo que se pretende con la aplicación ser su primera opción en compras en línea.

Una vez que hemos visto la interfaz que funciona como Home pasamos a las interfaces que realizaran el reconocimiento de objetos y texto, que se muestran al hacer clic en los botones que hay en Home de los mismos.

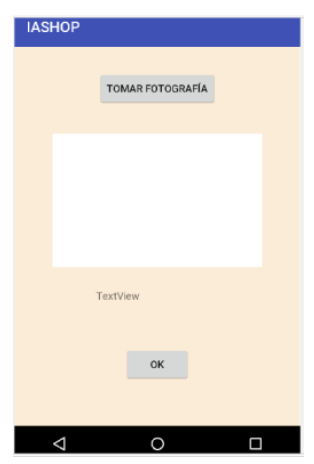

Figura 14 Detectar objetos

RAMÍREZ-SOLANO, Nestor de Jesús, NIETO-ROSALES, Ana Laura, MARTÍNEZ-GONZÁLEZ, Ana Stephany y VIDALHERNÁNDEZ, Cecilia. La inteligencia artificial al rescate de las pequeñas y medianas empresas. Revista de Tecnología Informática. 2019 


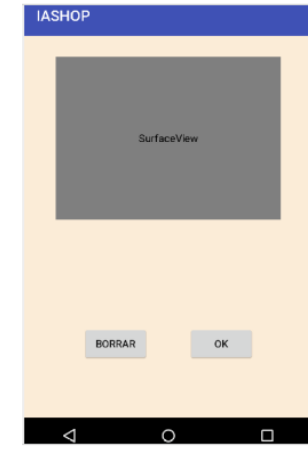

Figura 15 Detectar texto

En la Figura 14 tenemos la interfaz de detectar objetos el cual consiste en un botón en la parte superior con el nombre de tomar fotografía el cual a presionarlo accedemos a la cámara del dispositivo el cual presentara una pequeña modificación ya que al tomar la fotografía la aplicación le preguntara al usuario si está conforme con su fotografía o desea tomarla de nuevo.

Una vez que tomamos la fotografía de nuestro interés se mostrara en el cuadro blanco asignado para imágenes, una vez que la fotografía es asignada en este lugar la aplicación automáticamente la toma y la convierte en un Bitmap al que posteriormente se convierte en un arreglo de Bite para enviarlos al servicio de Google Vision en la nube, una vez en la nube la imagen es fragmentada en más capas de acuerdo a la intensidad de la luz, los colores, contornos y formas, todo eso hecho gracias a diversos vectores que le ayudan al sistema encontrar patrones en la imagen y poder catalogarla en una categoría en específico.

Esto es posible gracias al Deep leaming el cual es un subconjunto del aprendizaje máquina (Machine Learning) el cual es utilizado para problemas donde los métodos tradicionales de aprendizaje no logran un desempeño apropiado, el aprendizaje profundo se inspira en el cerebro para crear redes neuronales con un gran número de capas ocultas en comparación a las redes neuronales tradicionales.

Este tipo de topología permite a estas "Redes neuronales profundas" obtener patrones o características simples a partir de entradas complejas.

Generalmente cada una de las capas ocultas se encarga de nivel de abstracción diferente.
Por ejemplo, en el caso de detección de rostros las primeras capas se encargan de reconocer niveles de intensidad de luz, las capas posteriores se encargarían de características un poco más complejas como lo serían los bordes y los contornos, las siguientes capas escondidas se encargan de objetos más complejos como ojos, cejas, boca, nariz, etc., toda esta información es brindada a la capa final que es la encargada de la detección del rostro. El mismo principio es aplicado para el reconocimiento de objetos o animales.

Las técnicas de aprendizaje profundo no solo son usadas para problemas de clasificación, también tienen gran desempeño en problemas de aprendizaje no supervisado, como por ejemplo el reconocimiento de patrones, como lo es el reconocimiento de voz y de textos.

Bien una vez realizado todo el proceso anterior para la identificación del objeto el sistema de aprendizaje profundo en la nube nos regresara el nombre del objeto o una categoría en donde la ha clasificado la cual la respuesta se muestra al usuario en el cuadro del texto y si el usuario está de acuerdo con la aplicación en la forma que reconoció su fotografía presionara el botón de "OK" para acceder a la siguiente interfaz donde se mostrara una lista de los productos relacionados al objeto o categoría que reconoció la aplicación en la fotografía.

En cuando a la Figura 15 que representa la interfaz donde se hace el reconocimiento de texto el proceso de identificación es casi el mismo que el de reconocimiento de objetos solo que este se hace de una forma más eficiente ya que lo hace a través del reconocimiento de patrones por lo que su identificación la aplicación lo hace utilizando la cámara del dispositivo en forma de video para hacer zoom y autoenfoque al instante para el reconocimiento de texto de diverso tamaño, una vez que la aplicación reconoce todo el texto al que se enfocó la cámara del dispositivo muestra el texto reconocido en la parte inferior y si el usuario no está conforme con el texto detectado puede borrarlo con el botón "borrar", por el contrario si el usuario está conforme con el reconocimiento de texto puede presionar el botón de "OK" para acceder a los productos relacionados al texto reconocido. 
Para realizar ambos procesos anteriores tanto el reconocimiento de objeto como el de texto utilizamos la red neuronal pre-programada de Google llamada Cloud Vision el cual ya es una red neuronal diseñada para el reconocimiento de más de mil elementos y diversos tipos de texto, esto fue posible gracias a que Google utiliza todas las imágenes que diversos usuarios suben a la red, por lo que parte de esta red neuronal se puede utilizar de forma gratuita, esto se hizo con el fin de ahorrar tiempo ya que si se programa una red neuronal desde cero esto lleva mucho tiempo.

Por ejemplo, para hacer el reconocimiento de un solo objeto o letra se tienen que introducir un mínimo de treinta imágenes de diferentes colores y posiciones para entrenar a la red neuronal bien ahora esto multiplicado por la gran diversidad de productos que se pueden ofrecer en la aplicación el entrenamiento de la red neuronal desde cero será muy extenso, es por esta razón que es mejor utilizar una red neuronal ya pre-entrenada y solo mejorarla para hacerla más eficiente.

En las siguientes figuras se muestra de forma representativa como es que funciona una red neuronal para el reconocimiento de patrones.

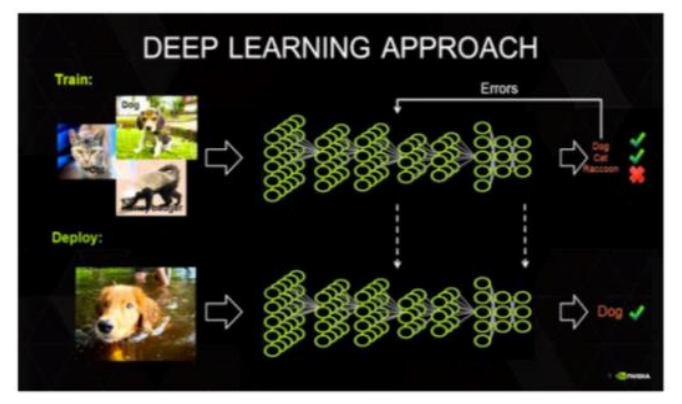

Figura 16 Imagen representativa del funcionamiento del Deep learning para la identificación de rostros Fuente https://www.quora.com/What-is-deep-learning

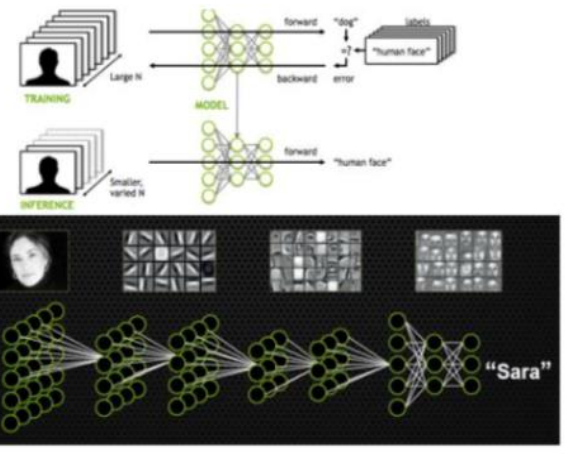

Figura 17 Imagen representativa del funcionamiento del Deep learning para la identificación de animales Fuente: https://www.quora.com/What-is-deep-learning
Una vez hecho lo anterior de la toma de fotografías del objeto de nuestro interés o el escaneo de texto y que el sistema identifique lo que se le a introducido la aplicación nos enviara a la siguiente interfaz donde se le mostrara al usuario un listado de los productos relacionados a la categoría en la que se clasifico la imagen introducida por el mismo usuario.

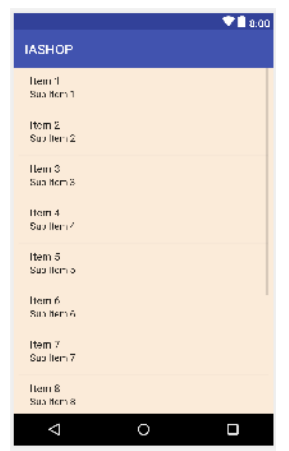

Figura 18 Catálogo de productos

En la Figura 18 se representa la interfaz donde se mostrará tanto el catálogo general, como el catalogo especifico de lo que el usuario busque a través del reconocimiento de texto $\mathrm{u}$ objetos por lo que se puede apreciar que el único elemento en la interfaz es el de un list view.

En los anexos se mostrará cómo se ven todas las interfaces ya funcionando sobre un dispositivo real.

En el cual la lista mostrara en ella el nombre del producto, una fotografía del mismo, la marca y el precio de cada uno.

El usuario podrá hacer clic sobre cualquier producto de la lista el cual lo llevará a la siguiente interfaz.

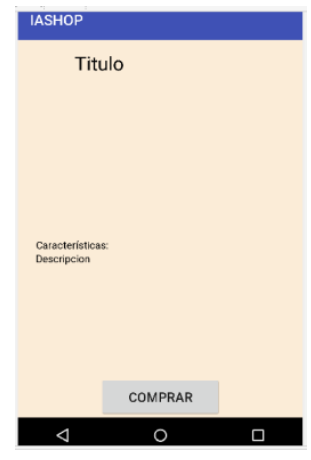

Figura 19 Interfaz de descripción 
Al hacer clic en algún elemento de la lista en la interfaz de la Figura 18 accederán a la interfaz de la Figura 19 en el cual cómo podemos apreciar en la parte superior mostrara el nombre del producto, justo debajo de esta se mostrara una fotografía más grande del producto seleccionado, después de la imagen aparece una etiqueta con la palabra "características" porque justo debajo de esta etiqueta aparecerán las características más relevantes del producto que le interesan a los usuarios conocer sobre ellos y finalmente en la parte inferior hay un botón con la palabra "comprar" el cual al momento que el usuario desee adquirir el producto la aplicación del formulario para él envió del producto y su pago, en caso contrario el usuario puede regresar a la interfaz del catálogo de productos.

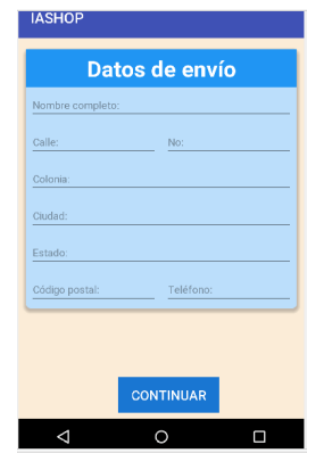

Figura 20 Interfaz de envió

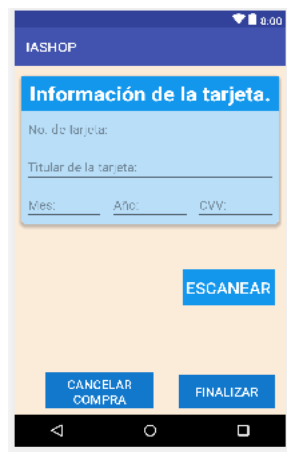

Figura 21 Interfaz de pago

En la Figura 20 se representa la interfaz que contiene el formulario de envió del producto en cual el usuario tiene que ingresar sus datos personales como lo son su nombre completo, su dirección completa, teléfono y código postal.

Una vez rellenado el formulario de envió debe de presionar el botón de continuar el cual lo enviara a la interfaz de la Figura 21 el cual es un formulario de su forma de pago en el cual podrá escanear su tarjeta con el botón "Escanear" y posteriormente rellenar los datos que hagan falta como los números de seguridad.
Si el usuario está satisfecho con todo podrá hacer clic en el botón "finalizar" para concluir con la compra, en caso contrario puede presionar el botón de "cancelar compra".

En ambos casos ya sea finalizar la compra o cancelarla la aplicación retornara al usuario a la interfaz de la Figura 12.

En cuando a la base de datos la base se va a mantener tal y como se mostró en el ciclo anterior con la diferencia de que la base de datos presentada anteriormente será solo como respaldo ya que a las consideraciones de la forma en la que la aplicación debe de trabajar se tomó la decisión de transferir parte de la base de datos que está en SQL a una base de datos NO SQL, ya que las base de datos NO SQL permite hacer actualizaciones al instante por lo que todos los dispositivos conectados a nuestra aplicación se pueden actualizar en cuestión de segundos y los usuarios que realicen compras si por alguna razón se desconectan de internet su información se mantendrá en espera hasta que el dispositivo se vuelva a conectar y se envié de forma segura, este tipo de bases de datos NO SQL son las que utilizan las aplicaciones de redes sociales más usadas actualmente como lo son Facebook, Instagram, YouTube, etc., por la gran cantidad de usuarios que manejan y el hecho de que se realizan más de un millón de publicaciones por minuto, es pensando en ese sentido que nosotros decidimos realizar una parte de nuestra base de datos en NO SQL las cuales son las tablas donde se registra los formularios de envió y de pago.

Como podemos apreciar el cambio que se hizo a las diferentes interfaces en este segundo ciclo son muy variadas y siendo estas últimas las preferidas por los representantes de los interesados, para ser las propuestas finales en esta primera versión de la aplicación denominada IASHOP la cual ayudará a las pequeñas y medianas empresas a vender sus productos, compitiendo a la par con las grandes transnacionales.

\section{Anexos}

Representación gráfica de la prueba de la aplicación. 


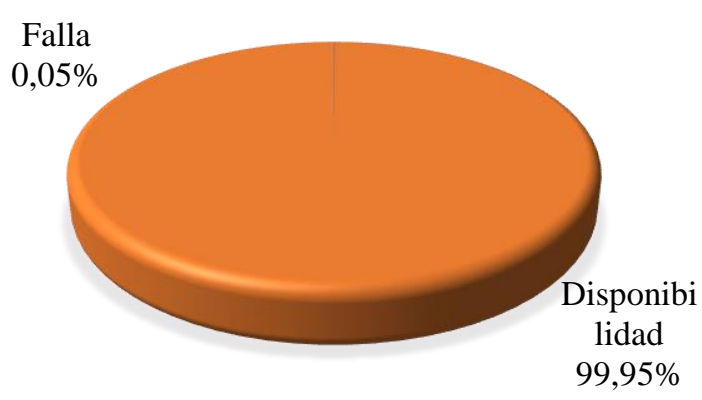

Gráfica 1 Gráfica de fallo

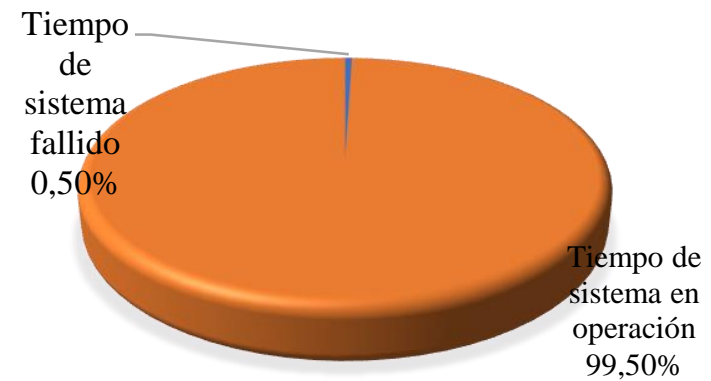

Gráfica 2 Gráfica del tiempo operacional

\section{Conclusiones}

En el mundo actual en el que todos estamos interconectados de una $u$ otra forma, las exigencias de los usuarios han convertido a las tecnologías que usamos en aplicaciones cada vez más amigables he intuitivas para comunicarnos con ellas como si de un semejante se tratara.

Como resultado del desarrollo de las pruebas de la aplicación, se tiene más del 99.9\% en la característica de fiabilidad ante los usuarios, así mismo durante el proceso de verificación y validación, como resultado de las pruebas se puede determinar que el tiempo de operación del sistema está garantizada con más del $99 \%$.

Por lo que se considera la aplicación como una herramienta útil para el uso en el proceso de compra y venta para un negocio pequeño, el cual no tiene los recursos económicos suficiente para la contratación de otras alternativas para la promoción y venta en línea de sus productos.

Por lo que la presente herramienta es una estrategia útil para ayudar a los pequeñas PyMES, y agilizar sus procesos de negocio en la comercialización de sus productos y servicios.

\section{Referencias}

Frey CB, Osborne MA. The future of employment: how susceptible are jobs to computerisation?. Technological Forecasting and Social Chan- ge. 2017 Jan 31;114:254-80.

López, T. B. (2007). Introducción a la inteligencia artificial. Instituto Tecnológico de Nuevo Laredo. Nuevo Laredo, Tamps. México.

Ocaña, Y., \& Valenzuela, L. (2018). La gestión del conocimiento y gobernanza. Mejores gobiernos, ciudadanos felices. Lima: Fondo editorial UCV.

Poole, D. Computational Intelligence: A Logical Approach. Nueva York: Oxford University Press. p. 1. Consultado el 13 de junio de 2018.

Predicting the Motion of a Robot Manipulator with Unknown Trajectories Based on an Artificial Neural Network, Sai Hong Tang, Chun Kit Ang, Mohd Khairol Anuar Bin Mohd Ariffin and Syamsiah Binti Mashohor, Septiembre del 2014

Russell S. and Norving P., "Inteligencia artificial: Un enfoque moderno". Prentice Hall. México. 1996. p. 2.

Ramos, L. (2014). Psicología cognitiva e inteligencia artificial: mitos y verdades. Avances en Psicología, 22(1), 21-27. Recuperado de: http://revistas.unife.edu.pe/index.php/avancesen psicologia/article/view/270

Rao, A. (2018). Una nueva etapa de globalización. Integración \& comercio, 44, 50$60 . \quad$ Recuperado de: https://dialnet.unirioja.es/servlet/articulo?codig $\mathrm{o}=6551931$.

Stone, P., Brooks, R., Brynjolfsson, E., Calo, R., Etzioni, O., Hager, G., \& Leyton- Brown, K. (2016). Artificial intelligence and life in 2030. One Hundred Year Study on Artificial Intelligence: Report of the 2015-2016 Study Panel. Recuperado de: https://ai100.stanford.edu/sites/default/files/ai_ 100_report_0831fnl.pdf.

RAMÍREZ-SOLANO, Nestor de Jesús, NIETO-ROSALES, Ana Laura, MARTÍNEZ-GONZÁLEZ, Ana Stephany y VIDALHERNÁNDEZ, Cecilia. La inteligencia artificial al rescate de las pequeñas y medianas empresas. Revista de Tecnología Informática. 2019 